\title{
EDITORIAL
}

\section{The silent epidemic among clinicians - Stress and Burnout}

\begin{abstract}
We have recently been inundated with epidemics such as the HIV epidemic, epidemic of non-communicable diseases, the obesity epidemic, and many more. However, as clinicians in a caring profession, I truly believe the epidemic that we are facing, the epidemic we really avoid acknowledging, because it shows our weakness
\end{abstract}

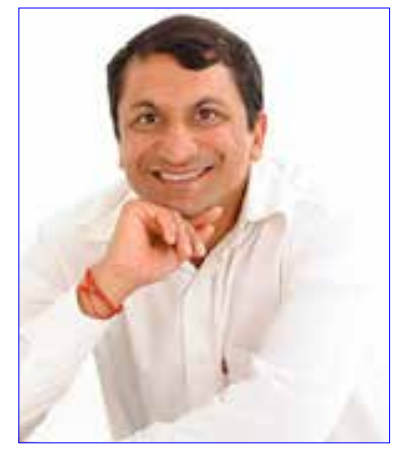
and is thus really silent, is stress, burnout and depression among doctors. ${ }^{1,2,3}$ Stress and burnout are high among all doctors, whether they work in the private or public health sector of South Africa. ${ }^{1,2}$ All these mental health challenges are mostly work related. However, stress and burnout stem from more than just our current work as they extend further into our nature, our character, and our personality traits. This ambitious work and goal driven, determined nature is what is still sought out by medical schools as necessary for admission. The candidates who give up everything else to concentrate on their studies, to extend their medical knowledge and competence at the expense of other compartments (aspects) to their lives, such as hobbies, sport, family, friends, spiritual activities, etc., are the candidates with typical type A personality traits. They inevitably score lower than non-medical peers for emotional and social intelligence. This suggests that even on entry to medical schools, these men and women are at risk of emotional burnout.

Although burnout is more common in the caring professions, it is also prevalent in other occupations. Thus, all-round development is necessary for everyone from an early age. Parents, teachers and other caregivers involved in a child's development need to place emphasis on this. Holidays or taking small infrequent breaks are only temporary solutions to the problem of burnout.

Doctors need to develop the other areas of their lives in order to be better people and doctors. ${ }^{4}$ The seven wellness areas which are physical health, emotional health, spiritual health, occupational health, intellectual health, social health and environmental health should be considered. It is essential to have more than one compartment to our lives to ensure a welldeveloped individual. Character development must begin in the pre-primary and primary school years, where other areas should be developed apart from academic excellence. Activities such as sport, music, reading, languages, art and theatre, writing or other hobbies such as fishing, gardening and movies should be explored. This is an extensive list and should be guided by the individual's interest. Holistic development is important.
Having more than one compartment to our lives is protective because if one aspect causes stress there are other aspects to fall back on for emotional support. What I refer to as 'compartment' is the other aspects of our life such as work, spiritual activities, hobbies, sport, family, etc. Too many clinicians believe and state that medicine is 'their entire life', 'their being', 'and 'their whole life'. This is bound to lead to stress and frustration. Most of us have witnessed our affected colleagues and friends coping pathologically with this stress and burnout. There are higher rates than the general population of alcohol abuse, medical drug abuse such as pethidine, other substance abuse, divorce and finally as a release from this hopelessness, doctors attempt and are sometimes successful in committing suicide. ${ }^{1}$

As a profession, let's talk about this epidemic, let's work on building resilience and coping strategies, let's agree we are vulnerable, let us select future clinicians who are more holistic and have compartments to their lives, and let us know and look out for the danger signs in ourselves and our colleagues. ${ }^{5,6}$ Besides training medical students to be competent clinicians, we need to prepare them in some way for life and the emotional/social challenges of being a doctor, developing coping mechanisms, developing resilience and then developing themselves holistically. I am not really sure how or when we will be able to do this but I do know we need to talk about this and discuss ways of addressing this epidemic, which is not going to disappear if we ignore it. Perhaps it can be done through electives or selectives that do not include only medical skill competencies. We need to first take care of ourselves and then we will be able to take better care of others.

I have often felt a prisoner at my practice, being indoors for most of the sunlight hours. One day looking out from the window of my consulting room, I wrote the following poem:

\section{A Doctor's Lament}

The palm leaves quivering

Dancing invitingly rhythmically in concert.

The Mdonni tree leaves being caressed

Gently by the breeze

The cloudless background of blue

All the more inviting

The blinds take up the rhythm

This invitation so consuming.

The thought of that caress

On my face, through my hair

Like dancing palms 
Makes my heart so full of lead

\section{My chest hollow}

My stomach sighs

All from behind the sealed window

\section{A prisoner}

Then what's my crime?

Oh how I would like to accept this invitation.

\section{Indiran Govender, 2004}

\section{References}

1. Govender I, Mutunzi E, Okonta HI. Stress among medical doctors working in public hospitals of the Ngaka Modiri Molema District (Mafikeng Health Region), North West Province. SAJP. May 2012.

2. Govender I, Joubert G, Oosthuizen SDW. Stress among General Practitioners in Kwa-Dukuza. African Journal of Primary Health and Family Practice. 2010

3. Guthrie E, Tattan T, Williams E, Black D, Bacliocotti H. Sources of stress, psychological distress and burnout in the psychiatrists: comparisons of junior doctors, senior registrars and consultants. Psychiatr Bull. 1999;23:207-12.

4. Couper ID. Approaching burnout. SA Fam Pract. 2005;47(2):5-8.

5. Lee FJ, Stewart M, Brown JB. Stress, burnout, and strategies for reducing them. Can Fam Physician. 2008;54:234-5.

6. Thomas LT, Valli A. Levels of occupational stress in doctors working in a South African public-sector hospital. S Afr Med J. 2006;96:1162-8. 